\title{
Mixed culture: encouraging cross-disciplinary collaboration and communication to enhance learning
}

\author{
Joanna Verran ${ }^{1}$ \\ Received: 25 February 2019 / Accepted: 10 May 2019 / Published online: 21 May 2019 \\ (C) Università degli studi di Milano 2019
}

\begin{abstract}
Purpose Undergraduate microbiology or biology students are not likely to be acquainted with the deterioration of cultural heritage. However, the topic provides an excellent opportunity for students to bring their existing 'non-scientific' skills and knowledge (such as history, geography, art, photography, and textiles) together with applied microbiology in order to develop their learning.

Methods A lecture on microbiology and art was given to first-year undergraduate students, who were then set an assignment to investigate a topic of their choice linking the two subjects, illustrated by a creative output.

Results The assignment enabled students to demonstrate their creativity, use their different talents, and engage in new learning. It proved very successful as a tool for engaging and inspiring the students to study microbiology and be more explorative in subsequent years. Indeed, for final year studies, some students continued to work on their 'art project'.

Interdisciplinary collaborations and new learning for the author have been additional benefits of this education project, with many varied outputs, including an 'Atlas of Biodeterioration', produced by researchers in the field.

Conclusion Biodeterioration of cultural heritage provides a rich focus for the development of informative and innovative activities in an educational setting.
\end{abstract}

Keywords Biodeterioration $\cdot$ Cultural heritage $\cdot$ Education $\cdot$ Creativity $\cdot$ Cross-disciplinary $\cdot$ Art

\section{Findings}

It is now generally accepted that the transfer of knowledge from lecturer to student is insufficient and inappropriate in today's learning environment. Active rather than passive learning stimulates students to develop a more flexible and holistic portfolio, encompassing transferable skills such as the ability to source new information, critical thinking, working across boundaries, and working in teams (Verran 2010). Creativity is an increasingly valued attribute (Henley 2018), but science students do not always recognize or utilize such talents.

Undergraduates arrive at University with a variety of skills, along with qualifications or expertise in subjects or topics that may be outside the direct focus of their programme of study.

Joanna Verran

j.verran@mmu.ac.uk

1 School of Healthcare Science, Manchester Metropolitan University, Manchester, UK
Nevertheless, these additional interests may well be of value in helping construct the overall skills portfolio for their future career. This short communication describes a learning experience designed for first-year undergraduate biology students, and the resultant outcomes and benefits. The aim of this experience was to encourage students to consider how art might be used to communicate science (in this case microbiology) to different audiences, thereby developing transferable skills. This would in turn demand understanding of scientific principles on their part, as well as different styles and modes of communication. As critical education theorists have pointed out, fostering effective communication is integral to supporting deeper forms of learning (Brookfield 2015; Mezirow 2000).

The activity began with a lecture that outlined the relationships between microbiology and art. Five key topics included: the biodeterioration of cultural heritage, the aesthetic impact of microorganisms, making art with microbes (for example https://www.asm.org/index.php/public-outreach/agar-art), infectious disease in classical art, and contemporary sci-art collaborations. The lecture (Verran 2008) encompassed 
unusual links between science and other disciplines such as architecture (comparison with virus structure), music (songs constructed to aid learning - www.jacket2.org/commentary/ infectious-disease-ditty), mathematics (for example fractal growth and colony morphology (Fujikawa and Matsushila 1989)), and psychology (for example the effect of stress on colony morphology (Shapiro 1995)). At the end of the lecture, an assignment was given, in which students were challenged to explore a subject where art and microbiology intertwined and produce a creative output that illustrated the relationship. Students could work in groups (up to three), or individually. They were required to discuss their idea with the tutor (author) so that assessment criteria could be clarified and negotiated where necessary. Usually 100 marks were divided into sections that addressed the underlying science (40), the rationale for the output (30), and the quality of the output itself (30) but there could be some agreed shift in emphasis of marks after discussion. An additional meeting was held during the term (the assignment was of 8 weeks of duration), but the tutor was available at other times if needed.

The lecture was delivered to almost 2000 students over a 7year period. The largest class size comprised around 250 students. There were five group assignments, from which students could choose one. Four focused on short summaries of properties of specific microorganisms, with the 'art assignment' being the fifth: in total 185 students selected that option. These students tended to be exceptionally enthusiastic and motivated by the assignment (author's observation). It is not easy to understand why students did or did not choose this assignment, but for three consecutive years, in monitoring and assessment documentation, the art project was the only assignment specifically complimented from over 20 different activities taken through the year, indicating that it was at least a memorable experience.

Biodeterioration of cultural heritage is a subject of which most first year biology undergraduates are unaware. However, it provides a fascinating example of applied microbiology that touches upon a wide range of other subjects - including history, art, geography, chemistry — whilst also embracing state of the art scientific research (studies on the microbiome, surface analysis techniques, conservation) as well as sci-art collaborations (for example www.saracraske.co.uk/biological-hermeneutics and www.edenproject.com/visit/whats-here/invisible-worldsexhibition/soil-exhibit). Although students could investigate any aspect of microbiology through this project (Verran 2013a), there were many who opted to explore cultural heritage in more detail, and these outputs are the focus of this short communication.

\section{First year undergraduate outputs}

It was apparent from the quality of the majority of the outputs, that the students took great care and considerable time in their production. Marks tended to be high because the students were absorbed in the project, committed to their creative process, and prepared carefully through discussion with their tutor. Each output received a mark, broken down into the three pre-determined components, with additional textual comments.

The range of outputs was impressive. For example, some students chose to produce artwork that represented a type of microorganism which they studied (Fig. 1a), or modified classical paintings to represent infectious disease more overtly (Fig. 1b). One student produced a three-dimensional representation of Van Gogh's Bedroom in Arles, which, when viewed from one angle, but not another, presented potential types of deterioration (Fig.1c, d). Others outputs included photography (Fig. 1e), experimental work (Fig. 1f), learning aides for teaching, and graphic reports on scientific studies such as the deterioration of plastic, or EU remediation projects (for example BIOBRUSH, https://cordis.europa.eu/project/rcn/ 61234/factsheet/en).

Each year, student outputs were exhibited, and sponsored prizes were awarded. Besides their marks, there were additional benefits: some images were used in peer-reviewed publications (for example Verran 2010, 2013a) or calendars (for example for the Society for Applied Microbiology [www. sfam.org.uk], or for the University), and students were always acknowledged. Student feedback was most complimentary: it was clear that they valued their work, and the opportunity to demonstrate different skills from those usually utilized, through the exploration of a new topic. It is not possible to assess the impact of this student activity (one assignment of three within one module of seven in the first year of study) on overall course performance. Perusal of assessment spreadsheets for different cohorts through their degree did not reveal any difference in unit mark obtained, subsequent subject choice, or final degree classification for those students who did the art assignment.

\section{Second-and final-year undergraduate projects}

Opportunities to develop the 'art project' were offered to students in their second and third years, utilizing different study modules and assessments, or through voluntary work. For example, one student who explored biofilms on buildings in Manchester extended the work for her final year project, by mapping biofilm growth on a city centre church, and isolating and identifying some of the microorganisms present (Fig. 2a). Collaboration with a human geographer who was studying the church (Edensor 2005) provided an additional crossdisciplinary experience.

A group of students visited Norton Priory, an historic monastery site, with gardens (www.nortonpriory.org), and also looked 
Fig 1 Artwork created by firstyear undergraduate biology students. a Page from notebook for a project on cyanobacteria (student Amy Ryder). b Modifying classical art to represent microorganisms; plague in the style of LS Lowry (students Kate Carolan and Emma Sheenan). c Imagined deterioration of Van Gogh's 'Bedroom in Arles: three dimensional model which presents deterioration viewed from the left (c), and not when viewed from the right (d) (student Benjie Bacall). e Photograph of a lichen colony in the shape of a heart for a calendar (student Samantha Taylor). f Experimental work to enable photography of algal bioluminescence (students Jessica Hampson and James Redfern)

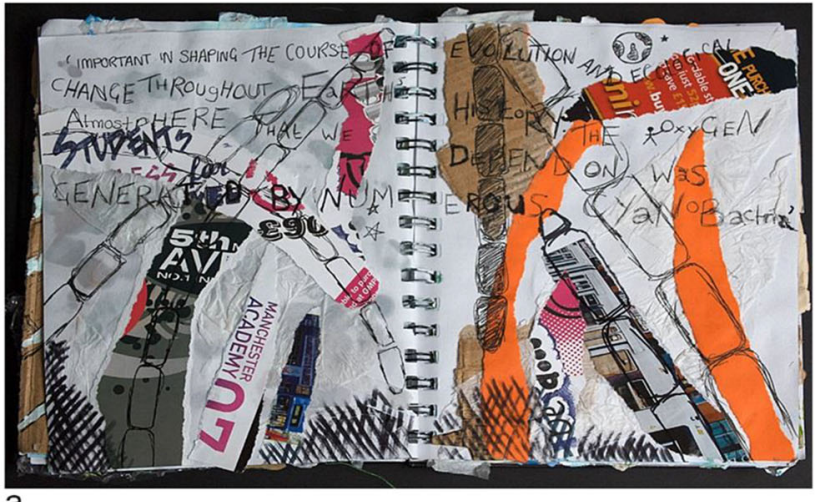

a
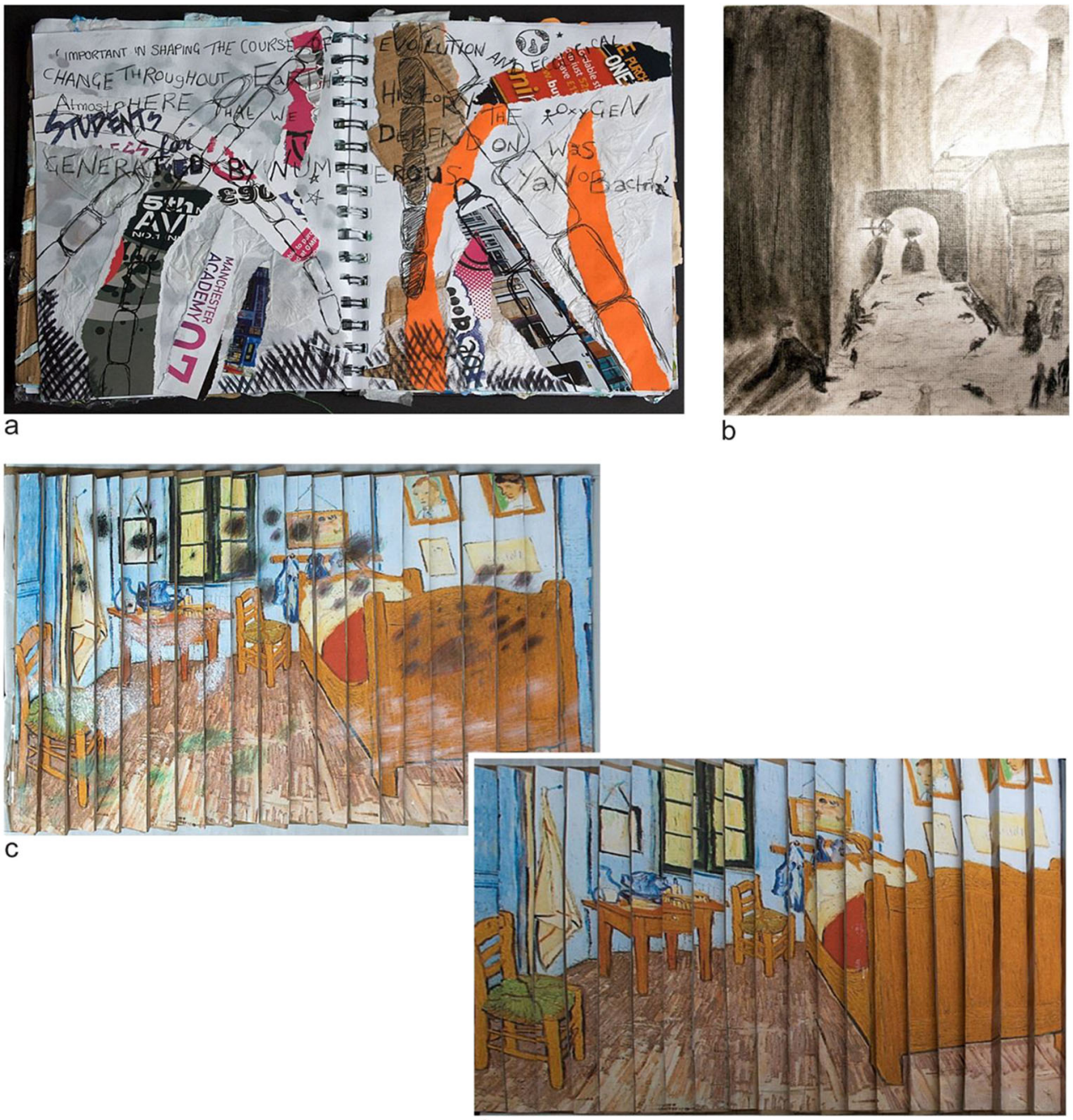

d

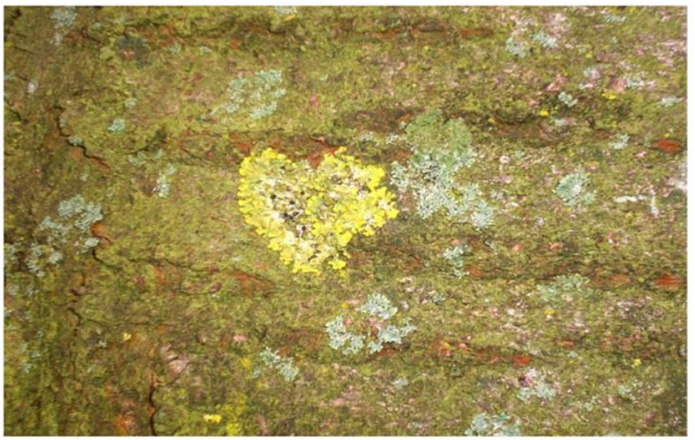

e

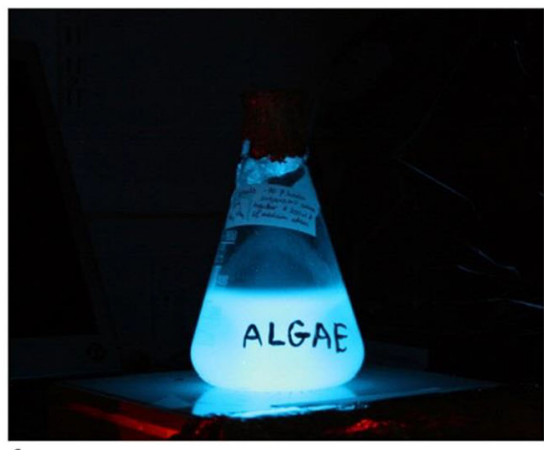

f

\section{Postgraduate studies and benefits to academic staff}

Inevitably collaborations arose between the author and colleagues or external organization as a result of this multidisciplinary project. One partly funded $\mathrm{PhD}$ project focused on the fungal deterioration of cine film (Bingley and Verran 2012, 2014), in collaboration with the North West Film Archive. Another fully funded $\mathrm{PhD}$ student worked on the ticipation in the mapping and measuring of colonies (Fig.2c, d).

at biofilm growth on ruins and sculptures with a view to developing a walk through the site, as part of a workthe International Biodeterioration and Biodegradation Society [www.ibbsonline.org]). An art student exploring the effect of pollution on lichen growth, using citizen science approaches (Gilbert 1986) then worked with the author to host an event for Manchester Science Festival, in order to encourage public par- 
Fig. 2 Continuation of art projects. a St Anne's Church Manchester, mapping biofilms (student Amy O'Toole). b Biofilm on St Anne's church Manchester (student Amy O'Toole). $\mathbf{c}$ Engaging the public with examination of lichen colonies (Joanne Keogh). d Artistic impressions of lichen colonies (Joanne Keogh). e Trentepohlia biofilms on a seaside chapel (Joanna Verran). f Turneresque biofilms on concrete wall (Joanna Verran)

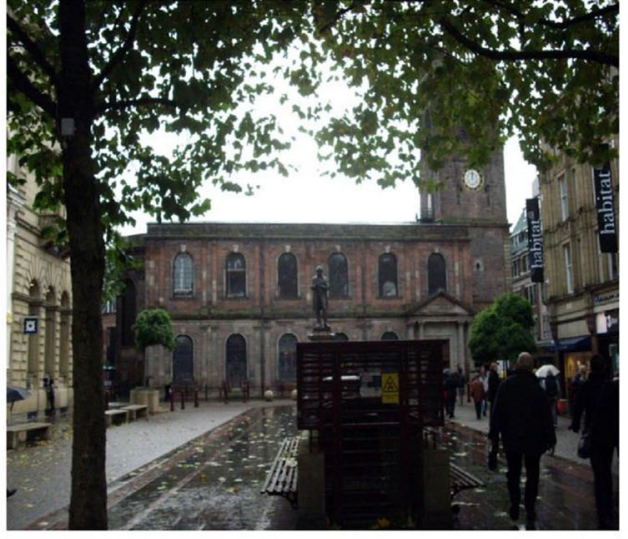

a

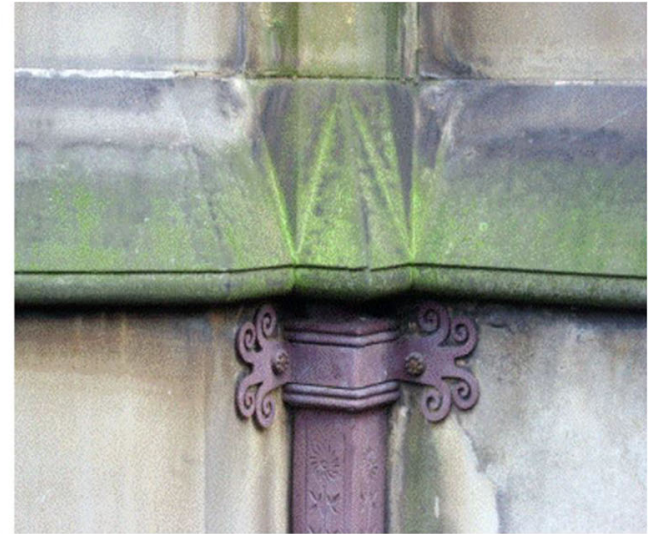

b

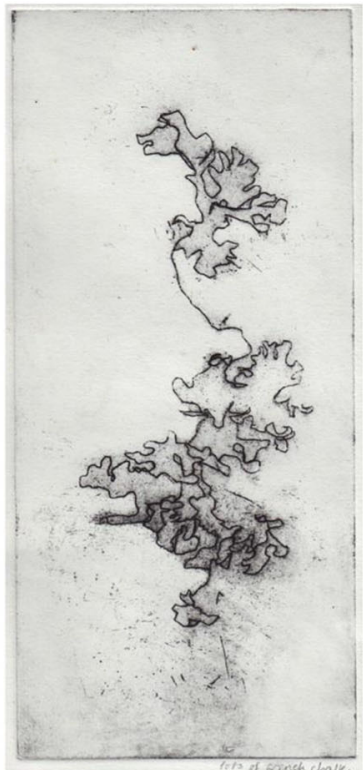

d

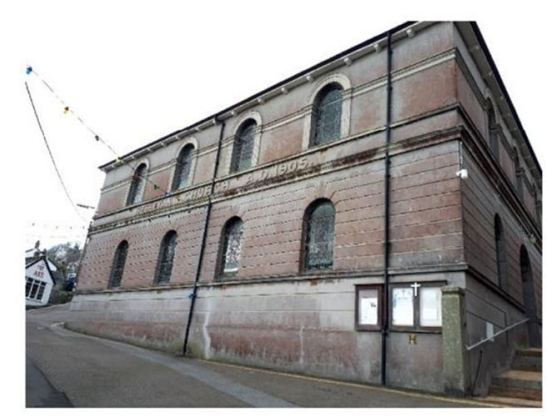

e

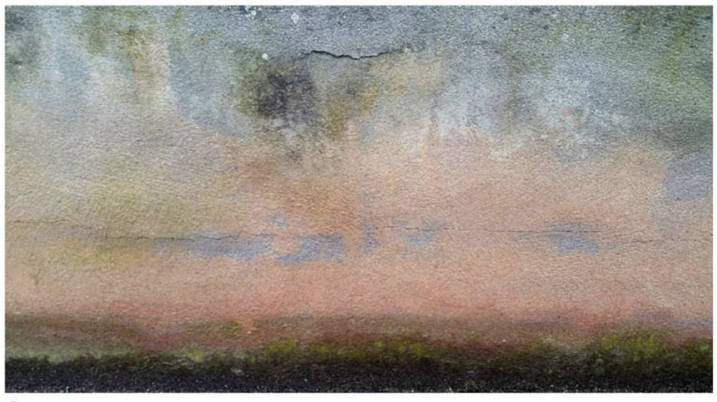

f production of learning materials to aid understanding of algae (Redfern et al. 2013; https://microbiologyonline.org/teachers/ society-books).

An increased awareness of biodeterioration and biodegradation on the part of the author was an additional and unforeseen benefit to this learning exercise, enabling acquisition of knowledge and embryonic photography skills, such as recognition of biofilm growth on buildings and monuments (Rindi and Guiri 2002) (Fig. 2e)—some even Turner-esque in appearance (Fig. 2f) - and monuments. Gathering together expertise present amongst members of the International Biodeterioration and Biodegradation Society enabled the production of a publication providing a simple overview of the many different substrates susceptible to biodeterioration (Verran 2013b), and a calendar published jointly with the Society for General Microbiology (now the Microbiology Society) raised the profile of this important research field further. 
Undergraduate education can be seen as a means to an end - a degree qualification, but it can also be viewed as a part of the journey of life-long learning. By supporting students to embrace all of their talents, we can make a valuable contribution to this continuous education. Combining art with science has been shown to be a way of enhancing understanding and communication, and knowledge of the contribution of microbiology to the conservation of cultural heritage was an additional and unforeseen benefit. Indeed, the 'microbiology and art' lecture and accompanying assignment provide a flexible model more focused towards a particular branch of microbiology —or indeed to any other field of science.

Acknowledgements The author would like to thank the students who engaged so enthusiastically in these projects, as well as the sponsors who supported some of the activities.

Funding Funding supported some of the activities described in this short communication. Funders were the Microbiology Society (one art exhibition and $\mathrm{PhD}$ studentship on algae), Society for Applied Microbiology (support for an event associated with artwork display), International Biodeterioration and Biodegradation Society summer studentship (Norton Priory project), EPSRC-funded Bridging the Gaps Nano-InfoBio project Grant Reference EP/H000291/1 (partial support of cinefilm deterioration project), Leica UK and Yakult UK (student prizes for art exhibitions).

\section{Compliance with ethical standards}

Research involving human participants All procedures performed in studies involving human participants were in accordance with the ethical standards of the faculty research committee and with the 1964 Helsinki declaration and its later amendments or comparable ethical standards.

Conflict of interest The author declares that she has no conflicts of interest.

\section{References}

Bingley G, Verran J (2012) Counts of fungal spores released during inspection of mouldy cinematographic film and determination of the gelatinolytic activity of predominant isolates. Int Biodet Biodeg $\mathrm{J}$ 84:381-387

Bingley G, Verran J (2014) Attack of the little green mould. J Film Preservation 90:11-18

Brookfield SD (2015) Teaching students to think critically about social media. New Dir Teach Learn 144:47-56

Edensor TJ (2005) Material culture 10: waste matter - the debris of industrial ruins and the disordering of the material world. $\mathrm{J}$ Material Culture 10:311-332

Fujikawa H, Matsushila M (1989) Fractal growth of Bacillus subtilis on agar plates. J Phys Soc Jpn 58:3875-3878

Gilbert OL (1986) Field evidence for an acid rain effect on lichens. Env Pollution 40:227-231

Henley D (2018) Creativity: why it matters. Elliott and Thompson Ltd, London

Mezirow J (2000) Learning to think like an adult. Core Concepts of Transformation Theory. In: Mezirow J, Associates (eds) Learning as transformation. Critical perspectives on a theory in progress. Jossey-Bass, San Francisco, CA, pp 3-33

Redfern J, Burdass D, Verran J (2013) Transforming a school learning exercise into a public engagement event: the good the bad and the algae. J Biol Ed 47:246-252

Rindi F, Guiry MD (2002) Diversity, life history and ecology of trentepohlia and printzina (Trentepohliales, Chorophyta) in urban habitats in Western Ireland 1. J Phycol 38:39-54

Shapiro JA (1995) The significance of bacterial colony patterns. BioEssays 17:597-607

Verran J (2008) Microbiology and art: an education opportunity. In: May E, Jones M, Mitchell J (eds) Heritage microbiology and Science: microbes, monuments and maritime materials. RSC, Cambridge UK, pp 293-299

Verran J (2010) Encouraging creativity and employability skills in undergraduate microbiologists. Trends Microbiol 18:56-58

Verran J (2013a) Mixed cultures: microbiology, art and literature. In: For the love of learning Ed T Bilman. Palgrave McMillan, Basingstoke, pp 21-28

Verran J (2013b) An Atlas of biodeterioration. Published by International Biodeterioration and Biodegradation Society. ISBN 9780992649807

Publisher's note Springer Nature remains neutral with regard to jurisdictional claims in published maps and institutional affiliations. 